\title{
Review Article \\ Cell Therapy in Ischemic Heart Disease: Interventions That Modulate Cardiac Regeneration
}

\author{
Maximiliano I. Schaun, Bruna Eibel, Melissa Kristocheck, Grasiele Sausen, \\ Luana Machado, Andreia Koche, and Melissa M. Markoski \\ Laboratório de Cardiologia Molecular e Celular (LCMC), Instituto de Cardiologia/Fundação Universitária de Cardiologia, \\ Porto Alegre, RS, Brazil \\ Correspondence should be addressed to Melissa M. Markoski; melissa.markoski@cardiologia.org.br
}

Received 14 August 2015; Revised 26 October 2015; Accepted 10 November 2015

Academic Editor: Stefania Montagnani

Copyright ( 2016 Maximiliano I. Schaun et al. This is an open access article distributed under the Creative Commons Attribution License, which permits unrestricted use, distribution, and reproduction in any medium, provided the original work is properly cited.

\begin{abstract}
The incidence of severe ischemic heart disease caused by coronary obstruction has progressively increased. Alternative forms of treatment have been studied in an attempt to regenerate myocardial tissue, induce angiogenesis, and improve clinical conditions. In this context, cell therapy has emerged as a promising alternative using cells with regenerative potential, focusing on the release of paracrine and autocrine factors that contribute to cell survival, angiogenesis, and tissue remodeling. Evidence of the safety, feasibility, and potential effectiveness of cell therapy has emerged from several clinical trials using different lineages of adult stem cells. The clinical benefit, however, is not yet well established. In this review, we discuss the therapeutic potential of cell therapy in terms of regenerative and angiogenic capacity after myocardial ischemia. In addition, we addressed nonpharmacological interventions that may influence this therapeutic practice, such as diet and physical training. This review brings together current data on pharmacological and nonpharmacological approaches to improve cell homing and cardiac repair.
\end{abstract}

\section{Introduction}

Cardiovascular events are among the leading causes of morbidity and mortality worldwide [1], and ischemic heart disease (IHD), caused by coronary obstruction, accounts for $80 \%$ of deaths from cardiovascular disease [2]. Although current pharmacological and surgical therapies have promoted a decrease in mortality rates due to acute myocardial infarction (AMI), they cannot promote the recovery of the injured area. Many patients develop chronic complications related to ischemia or myocardial necrosis, such as congestive heart failure [3]. Therefore, there is a need to develop new strategies to promote coronary revascularization and restoration of cardiac function.

Cell therapy has emerged as a promising alternative strategy, since it involves the delivery of cells with regenerative potential, mainly through the release of paracrine and autocrine important factors that contribute to cell survival, angiogenesis, and tissue remodeling [4-6]. The different lineages of stem cells, which have shown therapeutic potential for cardiovascular disease, can be broadly classified as bone marrow derived cell (BMDC) [7], bone marrow derived mesenchymal stem cells (MSC) [8], adipose derived mesenchymal cell (ADSC) [9], hematopoietic stem cells (HSC) [10], and cardiac stem cells (CSC) [11].

Despite the progress made since the first clinical trial conducted by Menasché et al. [12], cell therapy is far from being an established treatment for patients with myocardial infarction. The lack of robust results due to the low rate of survival and poor retention of transplanted cells in the injured tissue [13] as well as the cell type and route of administration seem to affect the treatment success $[14,15]$.

In recent years, there has been a large effort to elucidate the mechanisms of stem cells in regenerating damaged tissues. One of the key mechanisms is the release of signaling molecules of injury and capture of the stem cells, which are involved in proliferation, migration, differentiation, and engraftment in the target tissue [16]. This process is called cell homing and it is characterized by a molecular axis resulting from the interaction of the chemokine Stromal-Derived 
Factor-1 (SDF-1 or CXCL-12) with its specific receptor, the CXC chemokine receptor type 4 (CXCR-4) [16]. This pathway is influenced by various cytokines that modulate the immune system and the expression of growth factors as well as other molecules activated in response to physiological and pathological tissue regeneration.

Homing, in its magnitude, can be influenced both by heart disease (especially ischemic) and by therapeutic process either positively or negatively. Often, drugs used in the treatment of diseases inhibit cellular processes and consequently cell proliferation necessary for the tissue repair. In contrast, nonpharmacological interventions such as diet and physical activity can promote adequate conditions for cell homing [36]. In this context, activation of homing is the first step for tissue regeneration. The objective of this review is to discuss the main mechanisms of cell therapy for regeneration and angiogenesis in myocardial ischemia, focusing on the factors that may influence this therapeutic practice, such as diet, physical training, and pharmacological interventions.

\section{Pathological Factors Leading to Cardiac Remodeling}

According to World Health Organization (WHO), in 2011, IHD was the leading cause of death worldwide [37]. The ischemic process is characterized by the lack of blood supply to the tissue due to an obstruction caused by a thrombus formed by fatty deposits or blood clots. The main cause of ischemia is hypoxia, which leads to a lack of glucose and oxygen supply to cells and consequently to cell death. The clinical outcome of atherosclerosis is AMI, characterized by cell death by necrosis due to a lack of blood supply [38]. According to Antman et al. [38], in most cases, myocardial infarctions are transmural; that is, the ischemic necrosis involves the entire or almost the entire thickness of the ventricular wall in the distribution of a single coronary artery. Subsequently, the subendocardial infarct is an ischemic necrosis area limited to a third or, at most, a half of the ventricular wall [39]. The consequent loss of cardiomyocytes in AMI reduces the ability of cardiac tissue to pump blood from the left ventricle, leading to a progressive ventricular dilatation and reduced ejection capacity [39]. Patients who survive myocardial infarction become predisposed to chronic complications arising from repair mechanisms. In response to myocardial injury, a sequence of molecular and physiological responses is triggered, leading to ventricular remodeling and heart failure [40].

Activation of the immune response by AMI is characterized by migration and aggregation of cells of innate immunity, activation of the complement cascade, secretion of cytokines, such as interleukin-1 (IL-1), interleukin-2 (IL-2), interleukin6 (IL-6), and tumor necrosis factor type-alpha (TNF- $\alpha$ ) [41], and increase in T and B cells [42] and ROS [43, 44]. This phenomenon is the main responsible for the progressive functional losses that characterize cardiac ischemic events. However, the high release of cytokines and growth factors and the expression of adhesion molecules are also essential for the recruitment of progenitor cells (such as tissue-resident cells) from the bone marrow and their circulation to the injured organ $[45,46]$. This is characterized by the activation of a gradient of molecules and cells, which is also an evidence of the body's attempt to perform tissue repair.

Cell homing refers to this process whereby the cells are attracted to the chemoattractant gradient in response to ischemic tissue injury modulated by cytokines produced by damaged tissues or cells in apoptosis [47]. Progenitor cell homing is a physiological mechanism that occurs in all tissues for the replacement of cells. In this process, SDF-1 and its specific receptor, CXCR-4 [48], are the main molecules involved, allowing the adhesion and transmigration of cells, mainly circulating proangiogenic and hematopoietic stem cells [49]. In response to AMI, an increase in SDF-1 expression in the infarct and peri-infarct areas and a reduction in their levels to baseline values within 7 days have been demonstrated [50]. In AMI, SDF-1 also exerts its effects via activation of phosphatidylinositol 3-kinase (PI3K) and mitogen-activated protein kinase (MAPK) and hence activates the enzyme endothelial nitric oxide synthase (eNOS) and increases nitric oxide (NO) production [51]. Although the SDF-1/CXCR4 axis is activated by physiological mechanisms, including the replacement of cells in apoptotic processes, therapeutic procedures can modulate activation of these progenitor cells. In this way, treatment with injection of stem cells (cell therapy) may have an important action on the activation of homing process.

Many therapeutic strategies have been investigated to reduce the adverse effects of heart disease and associated risk factors, such as ventricular remodeling and consequent chronic heart failure (CHF) [52]. Studies have shown that stem cell therapy has the potential to regenerate myocardial tissue, induce angiogenesis, and thus improve the clinical course of the disease [8,53-55]. Table 1 shows the main clinical protocols, the cell source, the delivery process, and the outcomes in relation to the regenerative process in cell therapy.

\section{Cell Therapy for Angiogenesis in Myocardial Ischemia}

After the ischemic event, the restoration of blood flow and oxygen supply to the ischemic tissue results in the production of ROS, which are highly damaging to cells and can cause an exaggerated systemic inflammatory reaction $[44,56]$. Thus, reperfusion, required for the recovery of cell function, can aggravate the injury of ischemia, causing irreversible damage to tissue and cell death. Both prolonged ischemia and reperfusion may cause myocardial hibernation, characterized by the occurrence of chronic ventricular dysfunction. The pathophysiology of hibernating myocardium seems to be complex, involving repetitive postischemic dysfunction, which leads to phenotypic changes in myocardial cells, degeneration of myocytes, and tissue fibrosis [57]. Additionally, the condition is associated with a dynamic inflammatory process characterized by expression of the monocyte chemoattractant protein-1 (MCP-1) and continuous infiltration of leukocytes [58]. Regarding this molecular context, cardiology is undergoing one of the biggest revolutions in decades: a series of preclinical and clinical studies supporting 


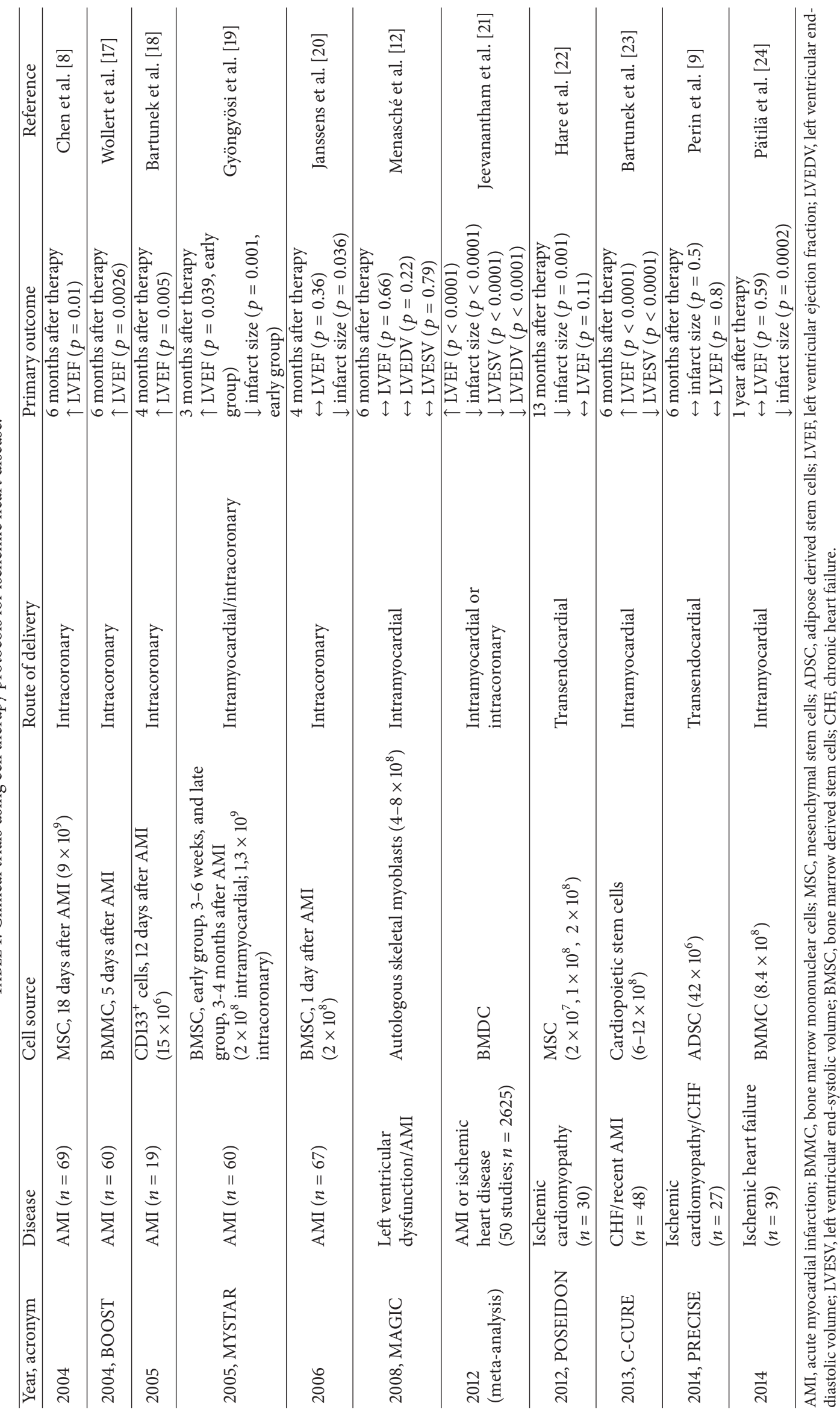


the hypothesis that the injured heart tissue could be repaired with stem cell administration and consequent formation of new vessels and myocytes [59]. Approaches in which the cells are used to produce factors promoting angiogenesis and regeneration of the ischemic tissue in the peri-infarct zone stand out [60].

Besides BMDC, MSC, ADSC, HSC, and CSC [23, 61], specific types of cells have been used for this purpose, such as those derived from skeletal myoblasts [12], induced pluripotent stem cells (iPSC) [62], and endothelial progenitor cells (EPC) [63]. These cells are used to stimulate angiogenesis by the expression of growth factors (vascular endothelial growth factor (VEGF), fibroblast growth factor, hepatocyte growth factor, granulocyte-colony stimulating factor, and angiopoietin-1 (Angpt-1)) [64-66] via a local paracrine mechanism in response to ischemia. These cells can also participate as precursor cells for vasculogenesis, acting as a vehicle to deliver therapeutic genes encoding angiogenic factors (VEGF, Angpt-1, and SDF-1/CXCR-4) and increasing the mobilization of EPC and subsequent neovascularization $[65,67]$.

In the scope of clinical cardiovascular research on neovascularization and cardiomyogenesis, considerable progress in the use of adult stem cells for cell transplantation has been made using HSC, BMDC, MSC, and EPC [60, 63]. Neovascularization in postmyocardial infarction patients can be mediated by the incorporation of vascular progenitor cells into the capillary or by the delivery of growth factors and cytokines that enhance angiogenesis by affecting mature endothelial cells $[68,69]$. In this context, humoral and paracrine factors released from stem cells and progenitor cells can improve cardiac function by reducing the apoptosis of cardiomyocytes or by activating CSC to increase cardiomyogenesis [70]. In relation to the effectiveness of the use of adult stem cells for cell transplantation, the variability in the reported findings may be partly explained by differences in the delivery methods, treatment logistics, and target diseases [71]. Despite positive effects on recovery of cardiac function in most of the studied groups, no significant changes in the ejection fraction have been reported [17, 18, 20, 72, 73], showing the need for technical refinements, standardization of scientific protocols, and validation of the findings.

In addition, a reduction in the number and function of autologous stem cells associated with comorbidities has been reported. Also, the paracrine effect on "diseased cells" and how these cells can be regenerated before transplantation has been investigated. In this regard, some experimental studies have identified alternative strategies to enhance cell survival, retention, integration, and homing [74]. These include genetic modification of stem cells prior to transplantation (cell transduction with prosurvival genes) and pretreatment of cells with other molecules (e.g., P38 inhibitors and eNOS) $[75,76]$, aiming at promoting tissue angiogenesis. Besides, experimental studies have focused on the use of cardiomyocyte implantation over the long term and its functional integration in rodents, motivating the translation of this approach to a nonhuman primate model of myocardial lesion [77]. More recently, cardiacderived stem cells originally postulated as cardiomyocyte progenitors have been used in clinical trials [11]. In these studies, these cells are obtained from myocardial biopsies and cultured for obtaining an autologous population [78]. Once the ischemic insult results in death of myocytes secondary to vascular damage and decreased regional blood flow, cell therapy seeks to promote angiogenesis and myogenesis in attempt to restore the physiological balance and to prevent the progression of heart failure. In light of current knowledge and the complexity of these mechanisms, the most effective treatment is positively influenced by the natural mechanisms of repair by the administration or local recruitment of cells capable of promoting angiogenesis and/or myogenesis [79]. Therefore, therapies for myocardial ischemia should target signaling molecules whose proregenerative properties are involved in therapeutic angiogenesis. Furthermore, the usual pharmacological treatments for cardiovascular diseases may also interfere in molecular pathways required for the success of cell therapy.

\section{Pharmacological Effects on Cell Therapy}

Advances in cardiovascular pharmacology in the last decades have been fundamental in reducing morbidity, mortality, and complications related to heart disease. IHD requires long term control medications. In clinical practice, the pharmacotherapy for IHD is based on the time of disease progression; in its acute stage, the myocardium undergoes reversible, morphological changes due to progressive injury represented by ischemic areas and necrosis and permanent damage in the chronic phase [80]. These stages are related to a variety of clinical presentations and potentially fatal complications requiring optimized pharmacological treatment.

However, the mechanism by which pharmacological intervention interacts with cell homing, survival, proliferation, and so on is poorly understood. Evidence shows that pharmacotherapy for the treatment of ischemic disease and underlying conditions may affect the success of cell therapy $[26,81]$. Preclinical data indicate a dual effect of pharmacological intervention which is sometimes beneficial by improving the regenerative potential of the stem cell therapy [29] and is sometimes harmful to the repair process $[30,31]$.

Factors that complicate the maintenance, survival, and consequently the paracrine action of implanted cells, as well as their cardiomyogenic potential, constitute limitations of cell therapy and have been investigated in regenerative medicine [82]. Both in vivo and in vitro studies have shown that certain drugs can improve the quality of the local microenvironment and facilitate the survival and biological behavior of implanted cells [26, 81, 82]. Moreover, pharmacological treatment may influence the cardiomyogenic transdifferentiation capacity of transplanted cells, with functional improvements such as increased left ventricular ejection fraction (LVEF) [34]. All these properties may be applicable to and effective in clinical practice.

Previous studies have evaluated molecular and cellular aspects as well as signaling pathways of cardiac repair after treatment of stem cells $[30,34]$. Different drugs used in clinical practice, including statins, aspirin, and beta-blockers, 
may act in signaling pathways involved in important cellular responses, including cell homing, activated by the SDF1/CXCR-4 axis [29]. This can have a significant impact on the progress of cell therapy, particularly in regenerative medicine focused on cardiac repair.

4.1. Statins. As previously mentioned, the ischemic process may be caused by blockage of coronary arteries by atherosclerotic plaques. These plaques are prone to rupture and expose substances that induce thrombosis, causing AMI. Thus, an approach for treatment and prevention of AMI consists of reducing the risk factors for atherosclerotic disease. Statins, among other effects, inhibit atherogenesis by changing circulating levels of plasma lipoproteins and are currently used in patients with high risk of cardiovascular events [83]. In addition, experimental data have shown that statins may have beneficial effects on LVEF and postmyocardial infarction remodeling $[84,85]$.

The pharmacological treatment with statins also presents pleiotropic effects, specifically in inhibiting inflammatory, fibrotic, and apoptotic processes [86]. Such effects may lead to an improvement in the local microenvironment, which in turn enhances the survival capacity and functional recovery of implanted cells. Using an animal model of myocardial infarction, Yang et al. [26] showed promising results in using a combination of stem cells and statins in IHD. This synergism may be effective in regeneration and repair of normal myocardial function and postmyocardial infarction morphology.

In addition, experimental studies have confirmed the beneficial effect of atorvastatin on postinfarction [25, 27]. Animals treated with atorvastatin followed by MSC transplantation showed enhanced survival of implanted cells and significant improvement in cardiac function $[25,27]$. The benefits of combination therapy (atorvastatin + MSC) can be at least partly mediated by increased expression and activation of the enzyme nitric oxide synthase (NOS), particularly the eNOS isoform [25]. Dong et al. demonstrated that atorvastatin leads to phosphorylation of protein kinase activated by adenosine monophosphate (AMPK), which results in the activation of eNOS [87].

Atorvastatin may also influence the signaling processes activated by the SDF-1/CXCR-4 axis [29]. Evidence indicates an increase of SDF-1 chemokine levels in animal models of myocardial infarction undergoing treatment with the drug, with consequent increase in CXCR- 4 receptor activation, providing antiapoptotic and anti-inflammatory effects. These effects may be, at least in part, eNOS/NO dependent. Furthermore, activation of SDF-1/CXCR-4 axis culminates in the activation of a cascade of signaling pathways responsible for mobilization and stem cell graft which contribute to the improvement of cardiac function [29].

Furthermore, administration of statins in patients with coronary artery disease (CAD) may have an influence on endothelial function. As demonstrated by Vasa et al. [28] in a group of patients with $\mathrm{CAD}$, atorvastatin treatment increased the serum levels of circulating EPC. Given the well-established role of EPC in the repair process after ischemic injury, these data suggest the potential of statins in improving neovascularization, which contributes to survival and maintenance of tissue viability in acute and chronic phases of myocardial ischemia, which may be beneficial for clinical cell therapy protocols.

4.2. Aspirin. Pharmacological therapy for the treatment or prevention of thrombosis or thromboembolism has been extensively used in clinical practice because of the high prevalence and serious consequences of these conditions, including AMI [88]. Antiplatelet agents are particularly important due to the essential role of platelets in the development of thrombosis. Aspirin belongs to the class of nonsteroidal antiinflammatory drugs, but it is widely used in low doses in noninflammatory conditions, such as cardiovascular disorders, primarily because of its antiplatelet effect [88]. However, in vitro experimental evidence has demonstrated that aspirin exerts other effects on cell signaling mechanisms [30,31]. This drug is of particular interest due to its ability to inhibit cell proliferation in vitro [89].

Aspirin can also induce cell apoptosis, mediated by mitochondrial caspase- 3 , which in turn requires the activation of Wnt $/ \beta$-catenin $[80,81]$. This signaling plays a critical role in self-renewal, differentiation, and survival of MSC [90]. In contrast to atorvastatin, the use of aspirin may also be associated with a decrease in the number of circulating EPC in humans, with a detrimental effect on neovascularization capacity. This effect may be dose- and time-dependent [32].

4.3. Beta-Blockers. Beta-blockers are prescribed to patients with myocardial infarction and/or hypertension. These drugs act in the blocking activity of $\beta$-adrenergic or $\alpha$-adrenergic receptors [91]. Beta-blockers provide a decrease in heart rate and myocardial contractility and an increase in myocardial oxygen consumption, significantly reducing the overall workload of the heart and leading to the improvement of ischemic symptoms [92].

Carvedilol, in addition to the nonselective blockade of $\beta 1$-adrenergic, $\beta 2$-adrenergic, and $\alpha 1$-adrenergic receptors, presents unique antioxidant properties by promoting the removal of superoxide anions and hydroxyl radicals [93]. In vitro studies demonstrate a protective effect of carvedilol against the deleterious effects of ROS induced by hydrogen peroxide and antiapoptotic effect on MSC [33]. Additionally, in AMI animal models, MSC transplantation in animals pretreated with carvedilol improved cardiac function, reduced fibrosis, increased angiogenesis and cardiomyocyte survival, and decreased caspase- 3 expression in ischemic heart tissue. Hassan et al. [33] suggested that the decrease in apoptosis may be due to the synergism of the antioxidant properties of carvedilol and paracrine signaling of MSC, which ultimately can lead to a reduction of apoptosis of remaining cardiomyocytes in peri-infarct regions. The combined treatment may be a more promising strategy for cardiac regeneration clinical practice to potential patients for cell therapy who are often treated with carvedilol.

Tissue regeneration requires the presence of cells with preserved proliferative capacity. A recent study demonstrated that propranolol is able to interfere with the proliferation of normal human endothelial cells and human cancer cell 
line [94]. This effect occurs through the modulation of key regulators of cell cycle progression and changes in the state of activation of specific and essential proteins to the maintenance of the cytoskeletal dynamics. In vitro treatment of cells with antagonist drugs of beta-adrenergic receptors may affect VEGF signaling, which uses NO as a second messenger. In addition, propranolol is able to block VEGFR2 phosphorylation, an important mitogenic regulator [94]. Data suggest that atenolol can also impair the vasculogenesis capacity of stem cells due to inhibition of NO generation of and proangiogenic growth factors, such as VEGF [95]. Vasculogenesis is strongly related to the signaling pathway mediated by VEGF.

Cardiac patients use beta-blocker drugs to reduce the cardiac workload and consequently reduce the energy consumption by the heart muscle. Cell transplantation may be impaired in these patients, with loss of proliferative, vasculogenetic, and angiogenetic efficiency by the implanted cells. Consequently, these cells lose their regenerative capacity, which defines the outcome of stem cell therapy for cardiac repair. Additionally, the stem cell microenvironment should also be considered, since beta-blockers drugs are commonly used continuously in order to maintain a desired plasma concentration for the expected therapeutic effect.

4.4. Other Drugs. Another reason for the limited effect of cell therapy for cardiac repair in clinical trials may be the low cardiomyogenic efficiency. Numasawa et al. [34] have investigated the in vitro and in vivo effect of angiotensin receptor blocker (ARB) drugs on cardiomyogenic capacity of human MSC derived from bone marrow. They found increased cardiomyogenic transdifferentiation efficiency in vitro and improved LVEF after infusion of pretreated MSC. In addition, immunohistochemical analysis revealed a significant increase in in vivo cardiomyogenesis. Examples of this class of drugs include losartan, valsartan, and candesartan, which act by preventing the action of angiotensin-II (AngII) (a potent vasoconstrictor agent) in its specific receptor in blood vessels [96]. Cells treated with ARB have shown greater in vitro transdifferentiation capacity, and transplantation of these cells promoted a significant improvement in cardiac function in AMI model [34].

The cardiomyogenic effect has also been observed with pioglitazone, a drug used to control blood glucose in diabetic patients whose risk factors are closely associated with the development of cardiovascular disease [35]. In this study, transplantation of cells pretreated with this drug improved the efficacy of in vivo cardiomyogenic transdifferentiation. Such effect possibly involved the activation of the nuclear receptor PPAR- $\gamma$, which regulates the expression of genes and affects the increase in cardiomyogenesis induced by pioglitazone.

The optimization of stem cell therapy for ischemic disease has been widely discussed. New evidence on how drug therapy and other interventions may affect cardiac repair could lead to new approaches to promote survival, maintenance, paracrine action, and cardiomyogenesis of the transplanted cells [82]. Understanding how cell therapy and pharmacotherapy interact could contribute to better targeting of cell therapy protocols, particularly those aimed at cardiac regeneration and repair. Table 2 summarizes some of the drugs commonly used in clinical practice and their influence on tissue regeneration after the administration of adult stem cells for the treatment of cardiovascular diseases. Interestingly, nonpharmacological interventions, including diets and physical activity, can also modulate the regenerative process and influence the stem cell therapy outcome.

\section{Nonpharmacological Interventions}

When it comes to prevention of cardiovascular diseases, we must consider a healthy lifestyle since childhood, including a balanced diet and regular physical exercise [97]. Once heart disease is established, therapeutic interventions should be planned according to the phase (acute or chronic) of the disease. The benefits of the combination of diet and regular physical training (cardiac rehabilitation) are potentially higher soon after an ischemic event and include positive effects on myocardial oxygen demand, endothelial function, autonomic tone, coagulation and clotting factors, inflammatory and lipoprotein markers, and development of coronary collateral vessels [98]. In chronic phase, healthy diet and physical training help maintain the physiological functions of the body, blood pressure, oxygen expenditure, and functional capacity, by adjusting the limitations imposed by the cardiac event $[99,100]$. In addition, it is well known that lack of exercise is among the major causes of chronic diseases, including the IHD. The main effects of diet and physical activity on cardiac regeneration are presented below.

5.1. Diet. In recent decades, the importance of diet and other lifestyle factors in the control of cardiovascular diseases has been strongly emphasized $[99,101]$. Since 1960, several studies have focused on the search for dietary indicators of atherogenicity, such as energy and cholesterol saturated and unsaturated fatty acids content.

Numerous randomized trials have demonstrated that appropriate dietary interventions can decrease [101] or even prevent the occurrence of various chronic diseases [102-104], including heart diseases. When Keys et al. [105] began to study the Mediterranean region, they found that although the local population consumed a large amount of fat (35\% to $40 \%$ of total daily calories), similar to Western countries, they had a low incidence of cardiovascular diseases. The authors described the "Mediterranean diet," which was rich in vegetables (fruits, vegetables, greenery, breads, and whole grains), fish and chicken (occasional red meat), red wine (in moderation and at meal times), dairy products (yogurt and cheese mainly), and fats, represented by nuts and olive oil in abundance. These findings were the basis for the study by de Lorgeril et al. [106], a randomized clinical trial of secondary prevention, aimed at testing the influence of the Mediterranean diet on patients' evolution after AMI. The study had been planned to be conducted for five years but was stopped after 27 months due to the benefits observed in the experimental group, with $70 \%$ decrease in overall mortality, primarily by reduction of coronary mortality. 


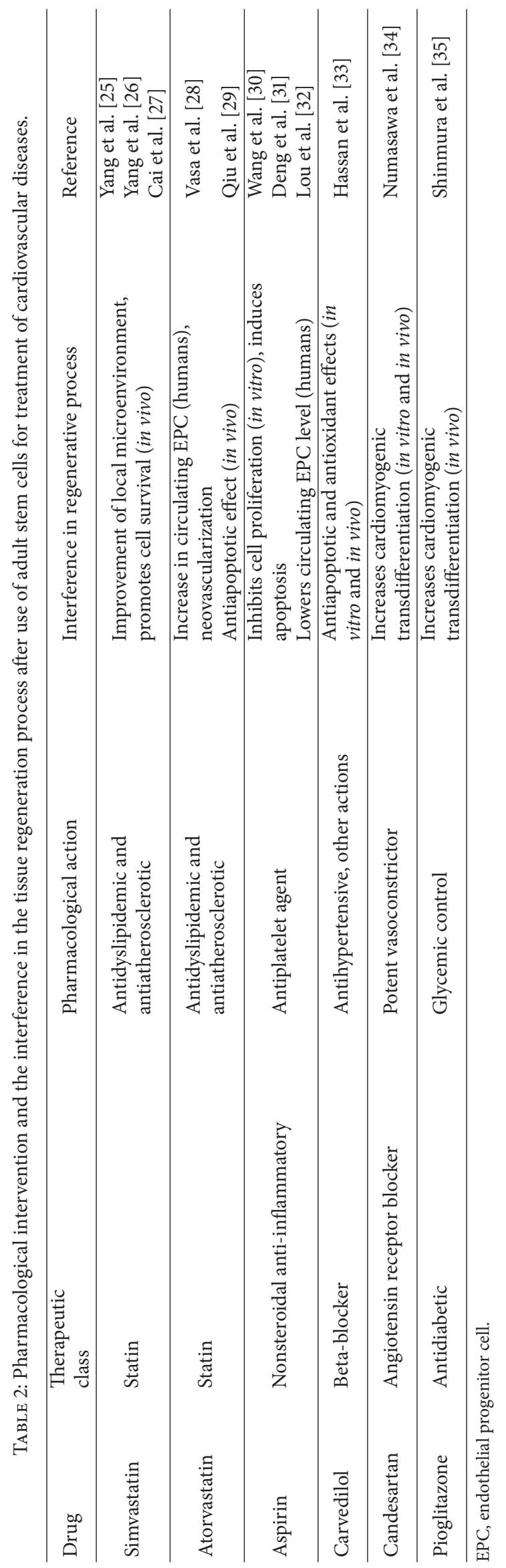


Several evidences of the benefits of the Mediterranean diet in secondary prevention have been shown since then $[107,108]$.

In this way, beneficial dietary factors have also been used in protocols of stem cell therapy, since it is believed that adult stem cells, present in different tissues, play a regenerative role following an injury or insult $[109,110]$. The challenge, however, is the low survival and differentiation of implanted cells, since most of these cells do not survive beyond 72 hours after transfusion [111]. Some studies have shown that this regeneration may be facilitated by a dietary adjuvant, such as the adoption of the Mediterranean diet.

Gorbunov et al. [111] treated CSC with resveratrol, a polyphenol with antioxidant and anti-inflammatory properties, and tested in a rat model left descending occlusion. The authors showed that the animals receiving the treated cells showed significant improvement in LVEF, fractional shortening, and cardiac output as compared to the control group after 1, 2, and 3 months of the procedure. The treated cells also had greater survival and engraftment, as well as increased expression of SDF-1 chemokine and important genes related to stress.

The intake of essential polyunsaturated fatty acids (PUFAs), as omega-3 ( $\omega-3)$ fatty acids, was shown to reduce the cardiovascular risk by inducing the release of prostaglandins, leukotrienes, and thromboxanes [112]. Essential fatty acids are needed for the synthesis of prostaglandins and proteins and play an important role in cell regeneration, defense mechanisms, and tissue regeneration [113]. PUFAs also generate precursors of pro- and anti-inflammatory molecules that can interfere in the physiology of chronic diseases and inflammatory processes. Linolenic acid, for example, is important in the transport of fat [114], contributing to the maintenance of the epidermal barrier integrity and accelerating healing processes. It also acts in the modulation of cell membrane by protecting against injury and acting as an immunogenic and restorative agent for the tissue, promoting chemotaxis, angiogenesis, humid environment, and tissue granulation, and thereby promotes cellular nutrition [115].

In obesity and type 2 diabetes, accumulation of nonessential fatty acids affects the regeneration process of skeletal muscle [116]. This may be critical for obese and diabetic patients who suffered from muscle damage caused by strenuous physical activity and consequent local ischemia. Other studies have shown that certain vitamins and minerals such as vitamins B3, C, and D, folic acid, selenium, and retinoic acid may promote the proliferation and differentiation of stem cells [117], thereby enhancing stem cell homing. Wong et al. [118] showed that physiological concentration of vitamin D promotes vascular regeneration, which was associated with an increase in the number of angiogenic myeloid cells, despite increased plasma levels of SDF-1.

5.2. Physical Training. Sedentary lifestyle is an important public health problem that is directly related to increased cardiovascular risk, which can be reduced by regular physical exercise [119]. However, despite the extensive characterization of the adaptations induced by exercise training, such as capillary density, enzyme profiles, and contractile proteins [120-122], there is still a great need for research on the molecular events underlying the physiological responses to physical training.

In CHF, regular physical exercise is associated with improvement of peripheral metabolism [123], oxygen consumption, electrocardiographic parameters [124], and mortality rates [125]. Aerobic training can prevent the loss of endothelium-dependent vasodilation and recover its function in sedentary middle-aged individuals and in men over 60 years of age [126]. Aerobic training was also associated with beneficial changes in blood pressure, lipid metabolism, glucose metabolism, body weight, and shear stress and with improvements in antioxidant defenses [119].

Gunning et al. [127] found that 6 weeks of aerobic training increased myocardial perfusion in patients with IHD. Consecutive sessions of training can promote cytoprotection by increasing the expression of heat shock proteins, mainly HSP72, in heart tissue and reducing apoptotic markers in murine model of ischemia/reperfusion [128]. Even if performed late after AMI, evidences in rats have shown that exercise training reduces heart dilation and scar development occurring after AMI [129], possibly because of its association with a better perfusion of heart tissue.

Physical training has been shown to be efficient in increasing the number and caliber of arterial vessels both in skeletal muscle and in myocardium, particularly in the injured heart tissue [130]. The activation of proangiogenic factors (cytokines, vascular growth factors, and NO) stimulates the mobilization and migration of circulating EPC and induces tissue neovascularization [131]. The study by Eleuteri et al. [132] with CHF patients demonstrated a higher mobilization of EPC, higher serum levels of angiopoietin-2 (Angpt-2), and an improvement in brachial artery dilation after 3 months of aerobic physical training. Similarly, a study from our group [133] showed that 12 weeks of moderate intensity aerobic training $\left(60-70 \%\right.$ of $\left.V_{\mathrm{O}_{2}} \max \right)$ was able to increase the flow-mediated dilation in brachial artery and the antioxidant response in healthy middle-aged subjects.

Even short duration physical training programs seem to be able to induce important endothelial adaptive responses. Concomitant with mobilization of EPC, there is a progressive rise in eNOS expression, an increase in neointimal formation, and a larger aortic diameter in mice trained for 28 days in running wheel [131]. In the study by Turan et al. [134], 3 weeks of aerobic training was able to increase the concentrations of $\mathrm{CD} 34^{+} / \mathrm{CD} 45^{+}$and $\mathrm{CD} 133^{+} / \mathrm{CD} 45^{+}$as well as the migratory capacity of EPC in patients at 14 days after AMI as compared to sedentary subjects. There was no difference in LVEF at rest between the groups. However, the increase of LVEF at peak stress was significantly higher after exercise training as compared to the control group.

Besides the direct influence on the endothelial function, physical training seems to optimize the regenerative capacity of the cardiac tissue. Nunes et al. [129] found that 8 weeks of aerobic training in a group of Wistar Kyoto rats after experimental induction of AMI improved the inflammatory and oxidative status by reducing the cardiac remodeling in animals with CHF. In patients with CHF, 8 weeks of aerobic training promoted an increase in LVEF, a higher mobilization of EPC, and an increase in SDF-1 expression, which induces 
angiogenesis and acts as a chemoattractant mediator for progenitor cells and represents the essential cytokine for cell homing [135]. Thus, in addition to cell mobilization, physical training is able to promote the regenerative potential of EPC. Furthermore, elderly individuals undergoing 12 weeks of physical training on a treadmill showed increased expression of the SDF-1 receptor CXCR-4 in EPC, which was associated with enhanced reendothelization capacity of these cells [136].

The regenerative response induced by physical training seems to be related to a modification in the inflammatory profile established by the AMI. When Wistar Kyoto rats with experimental AMI were submitted to 8 weeks of aerobic training on a treadmill, they showed reduced plasmatic levels of IL- 6 and TNF- $\alpha$ and higher levels of the anti-inflammatory cytokine IL-10 as compared to sedentary animals [129]. The IL-6 levels were positively associated with heart weight, indicating the effect of the inflammatory response on cardiac hypertrophy after AMI. Also, in patients with CHF, physical training was able to reduce plasma levels of inflammatory markers related to endothelial dysfunction [137]. Patients who underwent cycle ergometer training for 12 weeks showed lower plasma levels of MCP-1, intercellular soluble adhesion molecule (ICAM), and vascular cell adhesion molecules (VCAM), which suggests an inhibition of vascular inflammation by physical training.

In addition, changes in tissue environment induced by physical training seem to contribute to the regenerative process after cardiac ischemia. Under oxygen deprivation, the expression of SDF-1 gene is regulated by the hypoxia inducible factor-1 (HIF-1), which leads to a selective expression of the HIF-1 protein in the ischemic heart in proportion to the decrease in oxygen pressure [138]. HIF-1 positively regulates the expression of SDF-1, which stimulates adhesion, migration, and homing of CXCR- 4 positive progenitor cells in the ischemic tissue. In this context, it was demonstrated that 6 weeks of physical training on a treadmill was able to increase the expression of HIF-1 in heart tissue of Wistar Kyoto male rats [139]. This response to aerobic training mimics cell signaling triggered by the ischemic event of myocardial infarction.

AMI creates an inhospitable environment in cardiac tissue, characterized by increased ROS production, which in turn may be modulated by antioxidant responses induced by physical training. Six weeks of swimming was able to decrease superoxide radical levels and lipid oxidative damage and increase the expression of the antioxidant enzyme catalase (CAT) and the activity of glutathione peroxidase (GPx) in the left ventricle of male Wistar Kyoto rats [140]. These enzymes are specific for ROS, preventing significant changes in cellular REDOX state and functional impairment of the tissue [141].

Therefore, physical training may affect, in different ways, the cardiac tissue environment. This nonpharmacological intervention not only is involved in the prevention of cardiac ischemic events, mainly by maximizing endothelial function, but also plays a part in the regeneration of heart tissue after AMI. Cellular signaling in tissue repair and adaptive responses to physical training may minimize the functional losses resulting from ischemic damage. The systemic environment created by physical exercise is likely to be relevant for therapeutic approaches aiming at recovering cardiac function.

In nonpharmacological interventions, although positive effects on the recovery of cardiac function have been in the majority of treated groups, the improvement of LVEF $(\sim 15 \%)$ was not significant in all studies [72]. Apparently, the effects of physical training on IHD and CHF are related to the improvement in angiogenic responses, inflammatory profile, and functional capacity. Therefore, tissue regeneration including enhanced cell expression and adherence to target tissues provided by cell based therapies may be potentiated by these supporting approaches or by healthy behaviors [142].

\section{Future Directions}

In the last decade, the use of stem cells in cell therapy has been highlighted due to the capacity of these cells to promote tissue repair and enhance cell differentiation rate [143]. However, on long term, therapies using stem cells have shown low cell attachment to the graft, probably due to their low survival after injection into the patient. In contrast, the recovery of cardiac function is, in part, precisely related to the early action of these cells [144]. In this way, the need for new discoveries of molecular mechanisms to be applied in clinical practice dramatically increases. The low effectiveness of cell therapy in clinical trials with patients with heart disease $[145,146]$ may be attenuated by using these new findings in combination with gene therapy. A previous study from our group showed that the gene therapy provides continuous delivery of therapeutic proteins to the target site [147] and, at the same time, stem cells regulate the expression of growth factors by paracrine effect $[66,144]$. Ong et al. [148] performed a combined delivery of CPC and plasmids carrying HIF-1 gene in mice after experimental AMI. The combined therapy resulted in prolonged survival of transplanted CPC, reduced infarct area, and increased vascularization.

The regenerative response greatly depends on paracrine factors that can activate quiescent stem cells and/or induce the proliferation of the existing cardiomyocytes [11]. Exosomes secreted by MSC have emerged as possible factors responsible for the beneficial effects of paracrine signaling after cell therapy. As proposed by Lai et al. [149], purified exosomes reduced the size of the infarcted area in mice, and exosomes secreted by MSC showed a cardioprotective component, considered as a mediator for tissue repair. The interaction of exosomal microRNA of the resident cells with the transplanted ones can promote the survival of cells in the target tissue [148]. In this context, a lot of studies used exogenous molecules introduced to stem cells, aiming at promoting their overexpression or inhibiting specific cell mechanisms. Interestingly cardiac microRNAs were found to regulate the expression of paracrine factors by stem cells [150] and the angiogenic process [151].

Another alternative to increase the number of transplanted stem cells in the target organ is the cell sheet therapy. Cell sheet is an innovative technology that aims to obtain aligned cells in the graft, maintaining their biological and mechanical properties [152]. Several cell types have been 


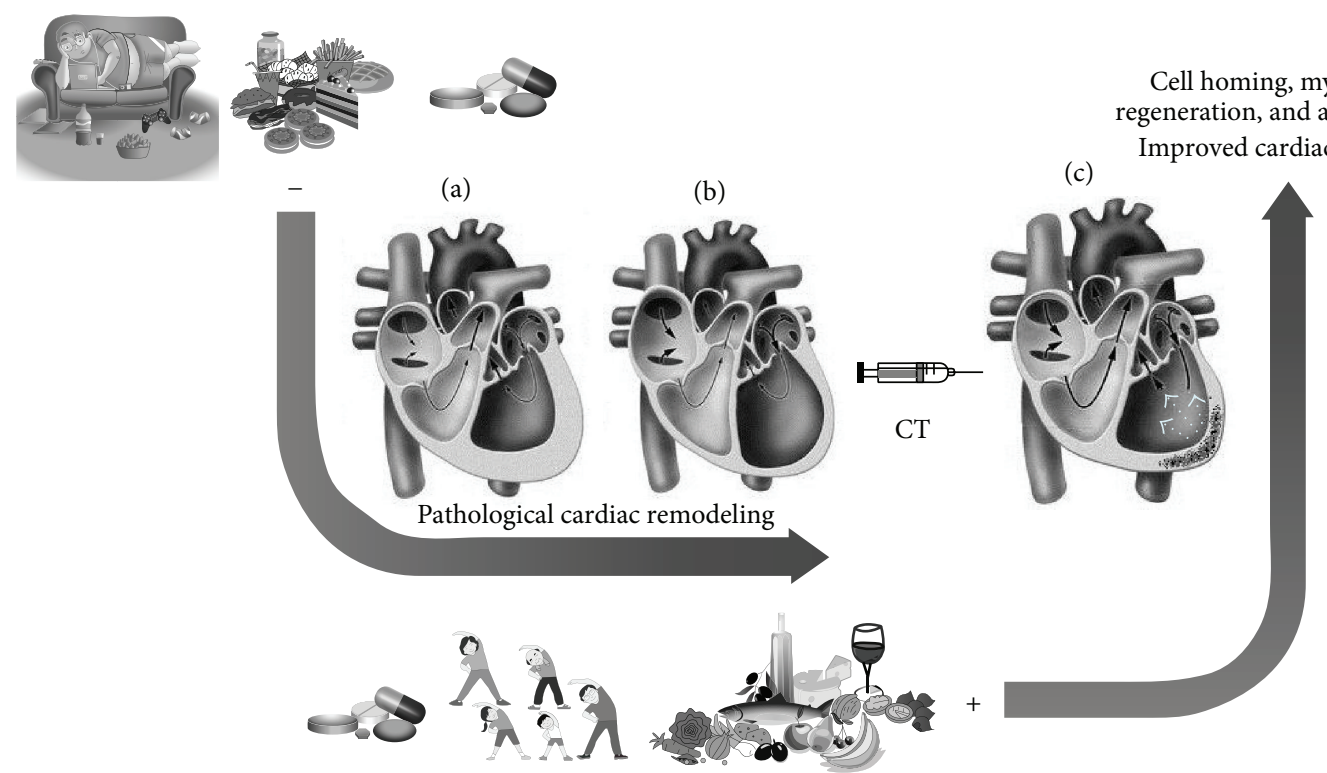

FIGURE 1: Factors that can modulate the cardiac regeneration in association with the stem cell therapy. The sedentary lifestyle and unhealthy dietary habits (as diets with elevated levels of fat and sugar) characterize risk factors that may contribute to the development of heart diseases, mainly due to the triggering of harmful issues that arise from the ischemic process which is generated in consequence of these behaviors. Therefore, the ischemia activates pathological cardiac remodeling mechanisms, the results of which may be the hypertrophy (a) or dilation (b) of the ventricular muscle, and both contribute to a decrease in ventricular ejection function. In an attempt to control the disease, there are commonly prescribed drugs that may interfere with mechanisms of cell proliferation and differentiation. These combined habits may adversely influence the effectiveness of cell therapy (CT). Subsequently, protocols that use stem cells are poorly effective in the regenerative process. Drugs that stimulate the antioxidant properties and control the inflammatory response, as well as the practice of physical activity and diets rich in cardioprotective elements (PUFAs, antioxidants, etc.), may balance the immune system. Besides that, a decrease in the ROS demand and increase of angiogenesis are stimulated by these approaches, providing a better environment for cell homing activation. This scenario intensifies mechanisms for cell regeneration and may lead to an increase in myocardial perfusion and improvement of the cardiac function (c). Thin black arrows indicate the blood flow in normal or damaged heart situation. White arrows suggest the improvement of the global contractility in the left ventricle after the regeneration process by stem cell enforcement (the figure was made from publicly available images).

studied to obtain cell sheets composed of viable cells [153, 154]. Experimental in vivo studies that used mesenchymal stem cell sheet and fibroblast have demonstrated improvement in muscle contractility, increase in vasculogenesis, and decrease in cardiac muscle fibrosis $[155,156]$.

Despite advances in the development of techniques aimed at increasing the effectiveness of cell therapy, improvement of cell homing is still a challenge. It would be necessary to identify safe and effective strategies to deliver the cells to the damaged organ and, at the same time, to improve the adherence of these cells in the target site. Then, it is crucial to establish the best source of cells and dose of injection [157]. As discussed by Garbern and Lee [11], the understanding of different responses observed in experimental and human models of cardiac regeneration and related pathways is determinant for the scientific progress in the field of regenerative cardiology.

In conclusion, many factors can positively or negatively influence and/or modulate the effectiveness of cell therapy in tissue recovery after damage in cardiovascular diseases, particularly in cardiac remodeling after ischemic injury (Figure 1). Cell therapy may have a significant role in the activation of homing mechanism, and therapeutic approaches are capable of activating progenitor cells, thereby improving heart tissue repair and ventricular remodeling. Current knowledge indicates that the most effective treatment available is positively influenced by the natural mechanisms of repair through the administration or local recruitment of cells capable of promoting angiogenesis and/or myogenesis. In this context, therapies for myocardial ischemia should target signaling molecules involved in angiogenesis. Besides, usual pharmacological treatments for cardiovascular diseases may also affect molecular pathways related to the success of cell therapy. The understanding of how cell therapy and pharmacotherapy interact could contribute to better targeting of clinical protocols. In addition to traditional pharmacological treatments, nonpharmacological interventions, such as diet and physical exercise, seem to be able to promote angiogenesis and generate a favorable environment for cell mobilization, survival, and repair.

\section{Disclosure}

The review was designed and conducted independently by the authors, without financial support. 


\section{Conflict of Interests}

The authors declare that there is no conflict of interests regarding the publication of this paper.

\section{Acknowledgment}

The authors would like to thank Ludmila M. Markoski for contributions in Figure 1.

\section{References}

[1] D. Mozaffarian, E. J. Benjamin, A. S. Go et al., "Heart disease and stroke statistics-2015 update: a report from the American Heart Association," Circulation, vol. 131, no. 4, pp. e29-e322, 2015.

[2] D. M. Lloyd-Jones, Y. Hong, D. Labarthe et al., "Defining and setting national goals for cardiovascular health promotion and disease reduction: the American Heart Association's strategic Impact Goal through 2020 and beyond," Circulation, vol. 121, no. 4, pp. 586-613, 2010.

[3] M. A. Pfeffer and E. Braunwald, "Ventricular remodeling after myocardial infarction. Experimental observations and clinical implications," Circulation, vol. 81, no. 4, pp. 1161-1172, 1990.

[4] L. Chen, E. E. Tredget, P. Y. G. Wu, Y. Wu, and Y. Wu, "Paracrine factors of mesenchymal stem cells recruit macrophages and endothelial lineage cells and enhance wound healing," PLoS ONE, vol. 3, no. 4, Article ID e1886, 2008.

[5] M. Gnecchi, Z. Zhang, A. Ni, and V. J. Dzau, "Paracrine mechanisms in adult stem cell signaling and therapy," Circulation Research, vol. 103, no. 11, pp. 1204-1219, 2008.

[6] J. S. Burchfield and S. Dimmeler, "Role of paracrine factors in stem and progenitor cell mediated cardiac repair and tissue fibrosis," Fibrogenesis and Tissue Repair, vol. 1, no. 1, article 4, 2008.

[7] A. Abdel-Latif, R. Bolli, I. M. Tleyjeh et al., "Adult bone marrowderived cells for cardiac repair: a systematic review and metaanalysis," Archives of Internal Medicine, vol. 167, no. 10, pp. 989997, 2007.

[8] S.-L. Chen, W.-W. Fang, F. Ye et al., "Effect on left ventricular function of intracoronary transplantation of autologous bone marrow mesenchymal stem cell in patients with acute myocardial infarction," The American Journal of Cardiology, vol. 94, no. 1, pp. 92-95, 2004.

[9] E. C. Perin, R. Sanz-Ruiz, P. L. Sánchez et al., "Adipose-derived regenerative cells in patients with ischemic cardiomyopathy: the PRECISE Trial," American Heart Journal, vol. 168, no. 1, pp. 88.e2-95.e2, 2014.

[10] C. E. Murry, L. J. Field, and P. Menasché, "Cell-based cardiac repair reflections at the 10 -year point," Circulation, vol. 112, no. 20, pp. 3174-3183, 2005.

[11] J. C. Garbern and R. T. Lee, "Cardiac stem cell therapy and the promise of heart regeneration," Cell Stem Cell, vol. 12, no. 6, pp. 689-698, 2013.

[12] P. Menasché, O. Alfieri, S. Janssens et al., "The myoblast autologous grafting in ischemic cardiomyopathy (MAGIC) trial: first randomized placebo-controlled study of myoblast transplantation," Circulation, vol. 117, no. 9, pp. 1189-1200, 2008.

[13] D. T. Vu and T. Kofidis, "Myocardial restoration: is it the cell or the architecture or both?" Cardiology Research and Practice, vol. 2012, Article ID 240497, 11 pages, 2012.
[14] V. Russo, S. Young, A. Hamilton, B. G. Amsden, and L. E. Flynn, "Mesenchymal stem cell delivery strategies to promote cardiac regeneration following ischemic injury," Biomaterials, vol. 35, no. 13, pp. 3956-3974, 2014.

[15] C. Gonzales and T. Pedrazzini, "Progenitor cell therapy for heart disease," Experimental Cell Research, vol. 315, no. 18, pp. 30773085, 2009.

[16] K. Wang, X. Zhao, C. Kuang et al., "Overexpression of SDF-1 $\alpha$ enhanced migration and engraftment of cardiac stem cells and reduced infarcted size via CXCR4/PI3K pathway," PLoS ONE, vol. 7, no. 9, Article ID e43922, 2012.

[17] K. C. Wollert, G. P. Meyer, J. Lotz et al., "Intracoronary autologous bone-marrow cell transfer after myocardial infarction: the BOOST randomised controlled clinical trial," The Lancet, vol. 364, no. 9429, pp. 141-148, 2004.

[18] J. Bartunek, M. Vanderheyden, B. Vandekerckhove et al., "Intracoronary injection of CD133-positive enriched bone marrow progenitor cells promotes cardiac recovery after recent myocardial infarction: feasibility and safety," Circulation, vol. 112, no. 9, supplement, pp. I178-I183, 2005.

[19] M. Gyöngyösi, I. Lang, M. Dettke et al., "Combined delivery approach of bone marrow mononuclear stem cells early and late after myocardial infarction: the MYSTAR prospective, randomized study," Nature Clinical Practice Cardiovascular Medicine, vol. 6, no. 1, pp. 70-81, 2009.

[20] S. Janssens, C. Dubois, J. Bogaert et al., "Autologous bone marrow-derived stem-cell transfer in patients with ST-segment elevation myocardial infarction: double-blind, randomised controlled trial," The Lancet, vol. 367, no. 9505, pp. 113-121, 2006.

[21] V. Jeevanantham, M. Butler, A. Saad, A. Abdel-Latif, E. K. Zuba-Surma, and B. Dawn, "Adult bone marrow cell therapy improves survival and induces long-term improvement in cardiac parameters: a systematic review and meta-analysis," Circulation, vol. 126, no. 5, pp. 551-568, 2012.

[22] J. M. Hare, J. E. Fishman, G. Gerstenblith et al., "Comparison of allogeneic vs autologous bone marrow-derived mesenchymal stem cells delivered by transendocardial injection in patients with ischemic cardiomyopathy: the POSEIDON randomized trial," The Journal of the American Medical Association, vol. 308, no. 22, pp. 2369-2379, 2012.

[23] J. Bartunek, A. Behfar, D. Dolatabadi et al., "Cardiopoietic stem cell therapy in heart failure: the C-CURE (Cardiopoietic stem Cell therapy in heart failURE) multicenter randomized trial with lineage-specified biologics," Journal of the American College of Cardiology, vol. 61, no. 23, pp. 2329-2338, 2013.

[24] T. Pätilä, M. Lehtinen, A. Vento et al., "Autologous bone marrow mononuclear cell transplantation in ischemic heart failure: a prospective, controlled, randomized, double-blind study of cell transplantation combined with coronary bypass," Journal of Heart and Lung Transplantation, vol. 33, no. 6, pp. 567-574, 2014.

[25] Y.-J. Yang, H.-Y. Qian, J. Huang et al., "Atorvastatin treatment improves survival and effects of implanted mesenchymal stem cells in post-infarct swine hearts," European Heart Journal, vol. 29, no. 12, pp. 1578-1590, 2008.

[26] Y.-J. Yang, H.-Y. Qian, J. Huang et al., "Combined therapy with simvastatin and bone marrow-derived mesenchymal stem cells increases benefits in infarcted swine hearts," Arteriosclerosis, Thrombosis, and Vascular Biology, vol. 29, no. 12, pp. 2076-2082, 2009.

[27] A. Cai, D. Zheng, Y. Dong et al., "Efficacy of Atorvastatin combined with adipose-derived mesenchymal stem cell transplantation on cardiac function in rats with acute myocardial 
infarction," Acta Biochimica et Biophysica Sinica, vol. 43, no. 11, pp. 857-866, 2011.

[28] M. Vasa, S. Fichtlscherer, K. Adler et al., "Increase in circulating endothelial progenitor cells by statin therapy in patients with stable coronary artery disease," Circulation, vol. 103, no. 24, pp. 2885-2890, 2001.

[29] R. Qiu, A. Cai, Y. Dong et al., "SDF-lalpha upregulation by atorvastatin in rats with acute myocardial infarction via nitric oxide production confers anti-inflammatory and anti-apoptotic effects," Journal of Biomedical Science, vol. 19, article 99, 2012.

[30] Y. Wang, X. Chen, W. Zhu, H. Zhang, S. Hu, and X. Cong, "Growth inhibition of mesenchymal stem cells by aspirin: involvement of the wnt/ $\beta$-catenin signal pathway," Clinical and Experimental Pharmacology and Physiology, vol. 33, no. 8, pp. 696-701, 2006.

[31] L. Deng, S. Hu, A. R. Baydoun, J. Chen, X. Chen, and X. Cong, "Aspirin induces apoptosis in mesenchymal stem cells requiring Wnt/ $\beta$-catenin pathway," Cell Proliferation, vol. 42, no. 6, pp. 721-730, 2009.

[32] J. Lou, T. J. Povsic, J. D. Allen et al., "The effect of aspirin on endothelial progenitor cell biology: preliminary investigation of novel properties," Thrombosis Research, vol. 126, no. 3, pp. el75e179, 2010.

[33] F. Hassan, S. Meduru, K. Taguchi et al., "Carvedilol enhances mesenchymal stem cell therapy for myocardial infarction via inhibition of caspase-3 expression," Journal of Pharmacology and Experimental Therapeutics, vol. 343, no. 1, pp. 62-71, 2012.

[34] Y. Numasawa, T. Kimura, S. Miyoshi et al., "Treatment of human mesenchymal stem cells with angiotensin receptor blocker improved efficiency of cardiomyogenic transdifferentiation and improved cardiac function via angiogenesis," STEM CELLS, vol. 29, no. 9, pp. 1405-1414, 2011.

[35] D. Shinmura, I. Togashi, S. Miyoshi et al., "Pretreatment of human mesenchymal stem cells with pioglitazone improved efficiency of cardiomyogenic transdifferentiation and cardiac function," STEM CELLS, vol. 29, no. 2, pp. 357-366, 2011.

[36] K. Ito and T. Suda, "Metabolic requirements for the maintenance of self-renewing stem cells," Nature Reviews Molecular Cell Biology, vol. 15, no. 4, pp. 243-256, 2014.

[37] The top 10 causes of death [database on the Internet], WHO, http://www.who.int/mediacentre/factsheets/fs310/en/.

[38] E. Antman, J.-P. Bassand, W. Klein et al., "Myocardial infarction redefined-a consensus document of The Joint European Society of Cardiology/American College of Cardiology committee for the redefinition of myocardial infarction: the Joint European Society of Cardiology/American College of Cardiology Committee," Journal of the American College of Cardiology, vol. 36, no. 3, pp. 959-969, 2000.

[39] E. Boersma, N. Mercado, D. Poldermans, M. Gardien, J. Vos, and M. L. Simoons, "Acute myocardial infarction," The Lancet, vol. 361, no. 9360, pp. 847-858, 2003.

[40] D. L. Mann, "Mechanisms and models in heart failure: a combinatorial approach," Circulation, vol. 100, no. 9, pp. 9991008, 1999.

[41] K. Ono, A. Matsumori, T. Shioi, Y. Furukawa, and S. Sasayama, "Cytokine gene expression after myocardial lnfarction in rat hearts: possible implication in left ventricular remodeling," Circulation, vol. 98, no. 2, pp. 149-156, 1998.

[42] S. W. Werns and B. R. Lucchesi, "Inflammation and myocardial infarction," British Medical Bulletin, vol. 43, no. 2, pp. 460-471, 1987.
[43] S. Kinugawa, H. Tsutsui, S. Hayashidani et al., "Treatment with dimethylthiourea prevents left ventricular remodeling and failure after experimental myocardial infarction in mice: role of oxidative stress," Circulation Research, vol. 87, no. 5, pp. 392-398, 2000.

[44] T. Ide, H. Tsutsui, S. Kinugawa et al., "Direct evidence for increased hydroxyl radicals originating from superoxide in the failing myocardium," Circulation Research, vol. 86, no. 2, pp. 152-157, 2000.

[45] B. E. Strauer, M. Brehm, T. Zeus et al., "Repair of infarcted myocardium by autologous intracoronary mononuclear bone marrow cell transplantation in humans," Circulation, vol. 106, no. 15, pp. 1913-1918, 2002.

[46] V. Schächinger, A. Aicher, N. Döbert et al., "Pilot trial on determinants of progenitor cell recruitment to the infarcted human myocardium," Circulation, vol. 118, no. 14, pp. 1425-1432, 2008.

[47] M. Tavassoli and C. L. Hardy, "Molecular basis of homing of intravenously transplanted stem cells to the marrow," Blood, vol. 76, no. 6, pp. 1059-1070, 1990.

[48] M. Shi, J. Li, L. Liao et al., "Regulation of CXCR4 expression in human mesenchymal stem cells by cytokine treatment: role in homing efficiency in NOD/SCID mice," Haematologica, vol. 92, no. 7, pp. 897-904, 2007.

[49] R. Kronenwett, S. Martin, and R. Haas, "The role of cytokines and adhesion molecules for mobilization of peripheral blood stem cells," STEM CELLS, vol. 18, no. 5, pp. 320-330, 2000.

[50] X. Hu, S. Dai, W.-J. Wu et al., "Stromal cell-derived factor$1 \alpha$ confers protection against myocardial ischemia/reperfusion injury: role of the cardiac stromal cell-derived factor- $1 \alpha$-CXCR 4 axis," Circulation, vol. 116, no. 6, pp. 654-663, 2007.

[51] D. J. Hausenloy and D. M. Yellon, "Reperfusion injury salvage kinase signalling: taking a RISK for cardioprotection," Heart Failure Reviews, vol. 12, no. 3-4, pp. 217-234, 2007.

[52] B. Vrtovec, G. Poglajen, and F. Haddad, "Stem cell therapy in patients with heart failure," Methodist DeBakey Cardiovascular Journal, vol. 9, no. 1, pp. 6-10, 2013.

[53] M. Hou, K.-M. Yang, H. Zhang et al., "Transplantation of mesenchymal stem cells from human bone marrow improves damaged heart function in rats," International Journal of Cardiology, vol. 115, no. 2, pp. 220-228, 2007.

[54] M. Mazo, V. Planat-Bénard, G. Abizanda et al., "Transplantation of adipose derived stromal cells is associated with functional improvement in a rat model of chronic myocardial infarction," European Journal of Heart Failure, vol. 10, no. 5, pp. 454-462, 2008.

[55] D. Orlic, J. Kajstura, S. Chimenti, D. M. Bodine, A. Leri, and P. Anversa, "Bone marrow stem cells regenerate infarcted myocardium," Pediatric Transplantation, vol. 7, supplement3, pp. 86-88, 2003.

[56] I. Francischetti, J. B. Moreno, M. Scholz, and W. B. Yoshida, "Leukocytes and the inflammatory response in ischemiareperfusion injury," Brazilian Journal of Cardiovascular Surgery, vol. 25, no. 4, pp. 575-584, 2010.

[57] A. Elsässer, M. Schlepper, W.-P. Klövekorn et al., "Hibernating myocardium: an incomplete adaptation to ischemia," Circulation, vol. 96, no. 9, pp. 2920-2931, 1997.

[58] N. G. Frangogiannis, S. Shimoni, S. M. Chang et al., "Evidence for an active inflammatory process in the hibernating human myocardium," The American Journal of Pathology, vol. 160, no. 4, pp. 1425-1433, 2002. 
[59] M. J. Lipinski, G. G. Biondi-Zoccai, A. Abbate et al., "Impact of intracoronary cell therapy on left ventricular function in the setting of acute myocardial infarction: a collaborative systematic review and meta-analysis of controlled clinical trials," Journal of the American College of Cardiology, vol. 50, no. 18, pp. 1761-1767, 2007.

[60] K. A. Gerbin and C. E. Murry, "The winding road to regenerating the human heart," Cardiovascular Pathology, vol. 24, no. 3, pp. 133-140, 2015.

[61] B. Assmus, S. Dimmeler, and A. M. Zeiher, "Cardiac cell therapy: lost in meta-analyses," Circulation Research, vol. 116, no. 8, pp. 1291-1292, 2015.

[62] T. J. Nelson, A. Martinez-Fernandez, S. Yamada, C. Perez-Terzic, Y. Ikeda, and A. Terzic, "Repair of acute myocardial infarction by human stemness factors induced pluripotent stem cells," Circulation, vol. 120, no. 5, pp. 408-416, 2009.

[63] A. Kawamoto, T. Tkebuchava, J.-I. Yamaguchi et al., "Intramyocardial transplantation of autologous endothelial progenitor cells for therapeutic neovascularization of myocardial ischemia," Circulation, vol. 107, no. 3, pp. 461-468, 2003.

[64] M. S. Penn, J. Pastore, T. Miller, and R. Aras, "SDF-1 in myocardial repair," Gene Therapy, vol. 19, no. 6, pp. 583-587, 2012.

[65] B. Eibel, C. G. Rodrigues, I. I. Giusti et al., "Gene therapy for ischemic heart disease: review of clinical trials," Brazilian Journal of Cardiovascular Surgery, vol. 26, no. 4, pp. 635-646, 2011.

[66] M. Lavu, S. Gundewar, and D. J. Lefer, "Gene therapy for ischemic heart disease," Journal of Molecular and Cellular Cardiology, vol. 50, no. 5, pp. 742-750, 2011.

[67] T. Asahara, C. Kalka, and J. M. Isner, "Stem cell therapy and gene transfer for regeneration," Gene Therapy, vol. 7, no. 6, pp. 451457, 2000.

[68] J. Rehman, J. Li, C. M. Orschell, and K. L. March, "Peripheral blood 'endothelial progenitor cells' are derived from monocyte/macrophages and secrete angiogenic growth factors," Circulation, vol. 107, no. 8, pp. 1164-1169, 2003.

[69] C. Urbich, A. Aicher, C. Heeschen et al., "Soluble factors released by endothelial progenitor cells promote migration of endothelial cells and cardiac resident progenitor cells," Journal of Molecular and Cellular Cardiology, vol. 39, no. 5, pp. 733-742, 2005.

[70] M. Gnecchi, H. He, O. D. Liang et al., "Paracrine action accounts for marked protection of ischemic heart by Akt-modified mesenchymal stem cells," Nature Medicine, vol. 11, no. 4, pp. 367-368, 2005.

[71] B.-E. Strauer and G. Steinhoff, "10 Years of intracoronary and intramyocardial bone marrow stem cell therapy of the heart: from the methodological origin to clinical practice," Journal of the American College of Cardiology, vol. 58, no. 11, pp. 1095-1104, 2011.

[72] R. T. Sant'anna, R. A. K. Kalil, A. S. Pretto Neto et al., "Global contractility increment in nonischemic dilated cardiomyopathy after free wall-only intramyocardial injection of autologous bone marrow mononuclear cells: an insight over stem cells clinical mechanism of action," Cell Transplantation, vol. 19, no. 8, pp. 959-964, 2010.

[73] V. Schächinger, B. Assmus, S. Erbs et al., "Intracoronary infusion of bone marrow-derived mononuclear cells abrogates adverse left ventricular remodelling post-acute myocardial infarction: insights from the reinfusion of enriched progenitor cells and infarct remodelling in acute myocardial infarction (REPAIR-AMI) trial," European Journal of Heart Failure, vol. 11, no. 10, pp. 973-979, 2009.

[74] V. J. Dzau, M. Gnecchi, and A. S. Pachori, "Enhancing stem cell therapy through genetic modification," Journal of the American College of Cardiology, vol. 46, no. 7, pp. 1351-1353, 2005.

[75] H. K. Haider, S. Jiang, N. M. Idris, and M. Ashraf, "IGF-1overexpressing mesenchymal stem cells accelerate bone marrow stem cell mobilization via paracrine activation of SDF$1 \alpha /$ CXCR4 signaling to promote myocardial repair," Circulation Research, vol. 103, no. 11, pp. 1300-1308, 2008.

[76] R. Sanz-Ruiz, E. Gutiérrez Ibañes, A. V. Arranz, M. E. Fernández Santos, P. L. Fernández, and F. Fernández-Avilés, "Phases I-III clinical trials using adult stem cells," Stem Cells International, vol. 2010, Article ID 579142, 12 pages, 2010.

[77] J. J. H. Chong, X. Yang, C. W. Don et al., "Human embryonicstem-cell-derived cardiomyocytes regenerate non-human primate hearts," Nature, vol. 510, no. 7504, pp. 273-277, 2014.

[78] T.-S. Li, K. Cheng, K. Malliaras et al., "Direct comparison of different stem cell types and subpopulations reveals superior paracrine potency and myocardial repair efficacy with cardiosphere-derived cells," Journal of the American College of Cardiology, vol. 59, no. 10, pp. 942-953, 2012.

[79] R. J. Hassink, A. B. de la Rivière, C. L. Mummery, and P. A. Doevendans, "Transplantation of cells for cardiac repair," Journal of the American College of Cardiology, vol. 41, no. 5, pp. 711-717, 2003.

[80] K. Thygesen, J. S. Alpert, and H. D. White, "Universal definition of myocardial infarction," European Heart Journal, vol. 28, no. 20, pp. 2525-2538, 2007.

[81] L. Song, Y.-J. Yang, Q.-T. Dong et al., "Atorvastatin enhance efficacy of mesenchymal stem cells treatment for swine myocardial infarction via activation of nitric oxide synthase," PLOS ONE, vol. 8, no. 5, Article ID e65702, 2013.

[82] T. E. Robey, M. K. Saiget, H. Reinecke, and C. E. Murry, "Systems approaches to preventing transplanted cell death in cardiac repair," Journal of Molecular and Cellular Cardiology, vol. 45, no. 4, pp. 567-581, 2008.

[83] S. Ebrahim, F. C. Taylor, and P. Brindle, "Statins for the primary prevention of cardiovascular disease," British Medical Journal, vol. 348, article g280, 2014.

[84] J. Bauersachs, P. Galuppo, D. Fraccarollo, M. Christ, and G. Ertl, "Improvement of left ventricular remodeling and function by hydroxymethylglutaryl coenzyme A reductase inhibition with cerivastatin in rats with heart failure after myocardial infarction," Circulation, vol. 104, no. 9, pp. 982-985, 2001.

[85] S. Hayashidani, H. Tsutsui, T. Shiomi et al., "Fluvastatin, a 3-hydroxy-3-methylglutaryl coenzyme a reductase inhibitor, attenuates left ventricular remodeling and failure after experimental myocardial infarction," Circulation, vol. 105, no. 7, pp. 868-873, 2002.

[86] A. Blum and R. Shamburek, "The pleiotropic effects of statins on endothelial function, vascular inflammation, immunomodulation and thrombogenesis," Atherosclerosis, vol. 203, no. 2, pp. 325-330, 2009.

[87] Q. Dong, Y. Yang, L. Song, H. Qian, and Z. Xu, "Atorvastatin prevents mesenchymal stem cells from hypoxia and serumfree injury through activating AMP-activated protein kinase," International Journal of Cardiology, vol. 153, no. 3, pp. 311-316, 2011.

[88] E. H. Awtry and J. Loscalzo, "Aspirin," Circulation, vol. 101, no. 10, pp. 1206-1218, 2000. 
[89] E. Castaño, M. Dalmau, M. Martí, F. Berrocal, R. Bartrons, and J. Gil, "Inhibition of DNA synthesis by aspirin in Swiss 3T3 fibroblasts," The Journal of Pharmacology and Experimental Therapeutics, vol. 280, no. 1, pp. 366-372, 1997.

[90] L. Ling, V. Nurcombe, and S. M. Cool, "Wnt signaling controls the fate of mesenchymal stem cells," Gene, vol. 433, no. 1-2, pp. $1-7,2009$.

[91] P. Larochelle, S. W. Tobe, and Y. Lacourcière, " $\beta$-Blockers in hypertension: studies and meta-analyses over the years," Canadian Journal of Cardiology, vol. 30, no. 5, supplement, pp. S16-S22, 2014.

[92] S. L. Kopecky, "Effect of beta blockers, particularly carvedilol, on reducing the risk of events after acute myocardial infarction," The American Journal of Cardiology, vol. 98, no. 8, pp. 1115-1119, 2006.

[93] A. Cargnoni, C. Ceconi, P. Bernocchi et al., "Reduction of oxidative stress by carvedilol: role in maintenance of ischaemic myocardium viability," Cardiovascular Research, vol. 47, no. 3, pp. 556-566, 2000.

[94] J. Stiles, C. Amaya, R. Pham et al., "Propranolol treatment of infantile hemangioma endothelial cells: a molecular analysis," Experimental and Therapeutic Medicine, vol. 4, no. 4, pp. 594604, 2012.

[95] F. Sharifpanah, F. Saliu, M. M. Bekhite, M. Wartenberg, and H. Sauer, " $\beta$-adrenergic receptor antagonists inhibit vasculogenesis of embryonic stem cells by downregulation of nitric oxide generation and interference with VEGF signalling," Cell and Tissue Research, vol. 358, no. 2, pp. 443-452, 2014.

[96] E. Viola, A. Coggiola Pittoni, A. Drahos, U. Moretti, and A. Conforti, "Photosensitivity with angiotensin II receptor blockers: a retrospective study using data from VigiBase," Drug Safety, vol. 38, no. 10, pp. 889-894, 2015.

[97] C. C. Cesa, S. M. Barbiero, O. Petkowicz Rde et al., "Effectiveness of physical exercise to reduce cardiovascular risk factors in youths: a randomized clinical trial," Journal of Clinical Medicine Research, vol. 7, no. 5, pp. 348-355, 2015.

[98] B. S. Heran, J. M. Chen, S. Ebrahim et al., "Exercise-based cardiac rehabilitation for coronary heart disease," Cochrane Database of Systematic Reviews, vol. 7, Article ID CD001800, 2011.

[99] F. W. Booth, C. K. Roberts, and M. J. Laye, "Lack of exercise is a major cause of chronic diseases," Comprehensive Physiology, vol. 2, no. 2, pp. 1143-1211, 2012.

[100] S. Sciarretta, P. Zhai, D. Shao et al., "Rheb is a critical regulator of autophagy during myocardial ischemia: pathophysiological implications in obesity and metabolic syndrome," Circulation, vol. 125, no. 9, pp. 1134-1146, 2012.

[101] B. V. Howard, L. Van Horn, J. Hsia et al., "Low-fat dietary pattern and risk of cardiovascular disease: the Women's Health Initiative Randomized Controlled Dietary Modification Trial," The Journal of the American Medical Association, vol. 295, no. 6, pp. 655-666, 2006.

[102] M. de Lorgeril and P. Salen, "The Mediterranean-style diet for the prevention of cardiovascular diseases," Public Health Nutrition, vol. 9, no. 1, pp. 118-123, 2006.

[103] The Diabetes Prevention Program, "Design and methods for a clinical trial in the prevention of type 2 diabetes," Diabetes Care, vol. 22, no. 4, pp. 623-634, 1999.

[104] J. Lindström, A. Louheranta, M. Mannelin et al., “The Finnish Diabetes Prevention Study (DPS): lifestyle intervention and 3year results on diet and physical activity," Diabetes Care, vol. 26, no. 12 , pp. 3230-3236, 2003.
[105] A. Keys, "Mediterranean diet and public health: personal reflections," The American Journal of Clinical Nutrition, vol. 61, no. 6, supplement, pp. 1321S-1323S, 1995.

[106] M. de Lorgeril, S. Renaud, N. Mamelle et al., "Mediterranean alpha-linolenic acid-rich diet in secondary prevention of coronary heart disease," The Lancet, vol. 343, no. 8911, pp. 1454-1459, 1994.

[107] H. Gardener, C. B. Wright, Y. Gu et al., "Mediterraneanstyle diet and risk of ischemic stroke, myocardial infarction, and vascular death: the Northern Manhattan Study," American Journal of Clinical Nutrition, vol. 94, no. 6, pp. 1458-1464, 2011.

[108] M. C. D. Thomazella, M. F. S. Góes, C. R. Andrade et al., "Effects of high adherence to mediterranean or low-fat diets in medicated secondary prevention patients," The American Journal of Cardiology, vol. 108, no. 11, pp. 1523-1529, 2011.

[109] H. M. Blau, T. R. Brazelton, and J. M. Weimann, “The evolving concept of a stem cell: entity or function?" Cell, vol. 105, no. 7, pp. 829-841, 2001.

[110] W. L. Fodor, "Tissue engineering and cell based therapies, from the bench to the clinic: the potential to replace, repair and regenerate," Reproductive Biology and Endocrinology, vol. 1, article 102, 2003.

[111] N. Gorbunov, G. Petrovski, N. Gurusamy, D. Ray, D. H. Kim, and D. K. Das, "Regeneration of infarcted myocardium with resveratrol-modified cardiac stem cells," Journal of Cellular and Molecular Medicine, vol. 16, no. 1, pp. 174-184, 2012.

[112] U. N. Das, "Essential fatty acids-a review," Current Pharmaceutical Biotechnology, vol. 7, no. 6, pp. 467-482, 2006.

[113] B. M. Shewchuk, "Prostaglandins and n-3 polyunsaturated fatty acids in the regulation of the hypothalamic-pituitary axis," Prostaglandins Leukotrienes and Essential Fatty Acids, vol. 91, no. 6, pp. 277-287, 2014.

[114] S. V. Martins, A. Madeira, P. A. Lopes et al., "Adipocyte membrane glycerol permeability is involved in the anti-adipogenic effect of conjugated linoleic acid," Biochemical and Biophysical Research Communications, vol. 458, no. 2, pp. 356-361, 2015.

[115] D. L. A. Greenway and K. G. H. Dyke, "Mechanism of the inhibitory action of linoleic acid on the growth of Staphylococcus aureus," Journal of General Microbiology, vol. 115, no. 1, pp. 233-245, 1979.

[116] J. Tumova, M. Andel, and J. Trnka, "Excess of free fatty acids as a cause of metabolic dysfunction in skeletal muscle," Physiological Research, In press.

[117] Y. Kawamori, Y. Katayama, N. Asada et al., "Role for vitamin D receptor in the neuronal control of the hematopoietic stem cell niche," Blood, vol. 116, no. 25, pp. 5528-5535, 2010.

[118] M. S. K. Wong, M. S. Leisegang, C. Kruse et al., "Vitamin D promotes vascular regeneration," Circulation, vol. 130, no. 12, pp. 976-986, 2014.

[119] Y. Higashi and M. Yoshizumi, "Exercise and endothelial function: role of endothelium-derived nitric oxide and oxidative stress in healthy subjects and hypertensive patients," Pharmacology and Therapeutics, vol. 102, no. 1, pp. 87-96, 2004.

[120] F. W. Booth and D. B. Thomason, "Molecular and cellular adaptation of muscle in response to exercise: perspectives of various models," Physiological Reviews, vol. 71, no. 2, pp. 541$585,1991$.

[121] J. Henriksson, M. M.-Y. Chi, C. S. Hintz et al., "Chronic stimulation of mammalian muscle: changes in enzymes of six metabolic pathways," The American Journal of Physiology-Cell Physiology, vol. 251, no. 4, part 1, pp. C614-C632, 1986. 
[122] R. S. Williams, "Mitochondrial gene expression in mammalian striated muscle. Evidence that variation in gene dosage is the major regulatory event," The Journal of Biological Chemistry, vol. 261, no. 26, pp. 12390-12394, 1986.

[123] J. R. Minotti, E. C. Johnson, T. L. Hudson et al., "Skeletal muscle response to exercise training in congestive heart failure," Journal of Clinical Investigation, vol. 86, no. 3, pp. 751-758, 1990.

[124] A. J. S. Coats, S. Adamopoulos, A. Radaelli et al., "Controlled trial of physical training in chronic heart failure. Exercise performance, hemodynamics, ventilation, and autonomic function," Circulation, vol. 85, no. 6, pp. 2119-2131, 1992.

[125] C. A. Emter, S. A. McCune, G. C. Sparagna, M. J. Radin, and R. L. Moore, "Low-intensity exercise training delays onset of decompensated heart failure in spontaneously hypertensive heart failure rats," The American Journal of Physiology-Heart and Circulatory Physiology, vol. 289, no. 5, pp. H2030-H2038, 2005.

[126] C. A. DeSouza, L. F. Shapiro, C. M. Clevenger et al., "Regular aerobic exercise prevents and restores age-related declines in endothelium-dependent vasodilation in healthy men," Circulation, vol. 102, no. 12, pp. 1351-1357, 2000.

[127] M. G. Gunning, J. Walker, S. Eastick, J. B. Bomanji, P. J. Ell, and J. M. Walker, "Exercise training following myocardial infarction improves myocardial perfusion assessed by thallium201 scintigraphy," International Journal of Cardiology, vol. 84, no. 2-3, pp. 233-239, 2002.

[128] J. C. Quindry, K. L. Hamilton, J. P. French et al., "Exerciseinduced HSP-72 elevation and cardioprotection against infarct and apoptosis," Journal of Applied Physiology, vol. 103, no. 3, pp. 1056-1062, 2007.

[129] R. B. Nunes, J. P. Alves, L. P. Kessler, and P. dal Lago, "Aerobic exercise improves the inflammatory profile correlated with cardiac remodeling and function in chronic heart failure rats," Clinics, vol. 68, no. 6, pp. 876-882, 2013.

[130] R. M. Melo, E. Martinho Jr., and L. C. Michelini, "Traininginduced, pressure-lowering effect in SHR: wide effects on circulatory profile of exercised and nonexercised muscles," Hypertension, vol. 42, no. 4, pp. 851-857, 2003.

[131] U. Laufs, N. Werner, A. Link et al., "Physical training increases endothelial progenitor cells, inhibits neointima formation, and enhances angiogenesis," Circulation, vol.109, no. 2, pp. 220-226, 2004.

[132] E. Eleuteri, A. Mezzani, A. Di Stefano et al., "Aerobic training and angiogenesis activation in patients with stable chronic heart failure: a preliminary report," Biomarkers, vol. 18, no. 5, pp. 418424, 2013

[133] M. I. Schaun, T. Dipp, J. Da Silva Rossato et al., "The effects of periodized concurrent and aerobic training on oxidative stress parameters, endothelial function and immune response in sedentary male individuals of middle age," Cell Biochemistry and Function, vol. 29, no. 7, pp. 534-542, 2011.

[134] R. G. Turan, M. Brehm, M. Köstering et al., "Effects of exercise training on mobilization of BM-CPCs and migratory capacity as well as LVEF after AMI," Medizinische Klinik, vol. 101, supplement 1, pp. 198-201, 2006.

[135] P. Sarto, E. Balducci, G. Balconi et al., "Effects of exercise training on endothelial progenitor cells in patients with chronic heart failure," Journal of Cardiac Failure, vol. 13, no. 9, pp. 701708, 2007.

[136] W.-H. Xia, J. Li, C. Su et al., "Physical exercise attenuates age-associated reduction in endothelium-reparative capacity of endothelial progenitor cells by increasing CXCR4/JAK-2 signaling in healthy men," Aging Cell, vol. 11, no. 1, pp. 111-119, 2012.

[137] S. Adamopoulos, J. Parissis, C. Kroupis et al., "Physical training reduces peripheral markers of inflammation in patients with chronic heart failure," European Heart Journal, vol. 22, no. 9, pp. 791-797, 2001.

[138] D. J. Ceradini, A. R. Kulkarni, M. J. Callaghan et al., "Progenitor cell trafficking is regulated by hypoxic gradients through HIF-1 induction of SDF-1," Nature Medicine, vol. 10, no. 8, pp. 858-864, 2004.

[139] B. Rinaldi, M. Donniacuo, L. Sodano et al., "Effects of sildenafil on the gastrocnemius and cardiac muscles of rats in a model of prolonged moderate exercise training," PLoS ONE, vol. 8, no. 7, Article ID e69954, 2013.

[140] C. A. Pinho, C. B. Tromm, A. M. V. Tavares et al., "Effects of different physical training protocols on ventricular oxidative stress parameters in infarction-induced rats," Life Sciences, vol. 90, no. 13-14, pp. 553-559, 2012.

[141] B. Halliwell, "Oxidative stress, nutrition and health. Experimental strategies for optimization of nutritional antioxidant intake in humans," Free Radical Research, vol. 25, no. 1, pp. 57-74, 1996.

[142] A. Ghorbani and H. Naderi-Meshkin, "The endocrine regulation of stem cells: physiological importance and pharmacological potentials for cell-based therapy," Current Stem Cell Research \& Therapy, vol. 10, p. 1, 2015.

[143] V. Karantalis and J. M. Hare, "Use of mesenchymal stem cells for therapy of cardiac disease," Circulation Research, vol. 116, no. 8, pp. 1413-1430, 2015.

[144] J. Liu, K. H. Narsinh, F. Lan et al., "Early stem cell engraftment predicts late cardiac functional recovery: preclinical insights from molecular imaging," Circulation: Cardiovascular Imaging, vol. 5, no. 4, pp. 481-490, 2012.

[145] S. A. Fisher, C. Doree, A. Mathur, and E. Martin-Rendon, "Meta-analysis of cell therapy trials for patients with heart failure," Circulation Research, vol. 116, no. 8, pp. 1361-1377, 2015.

[146] M. Gyöngyösi, W. Wojakowski, P. Lemarchand et al., "Metaanalysis of cell-based cardiac studies (ACCRUE) in patients with acute myocardial infarction based on individual patient data," Circulation Research, vol. 116, no. 8, pp. 1346-1360, 2015.

[147] I. I. Giusti, C. G. Rodrigues, F. B. Salles et al., "High doses of vascular endothelial growth factor 165 safely, but transiently, improve myocardial perfusion in no-option ischemic disease," Human Gene Therapy Methods, vol. 24, no. 5, pp. 298-306, 2013.

[148] S.-G. Ong, W. H. Lee, M. Huang et al., "Cross talk of combined gene and cell therapy in ischemic heart disease: role of exosomal microRNA transfer," Circulation, vol. 130, supplement 1, no. 11, pp. S60-S69, 2014.

[149] R. C. Lai, F. Arslan, M. M. Lee et al., "Exosome secreted by MSC reduces myocardial ischemia/reperfusion injury," Stem Cell Research, vol. 4, no. 3, pp. 214-222, 2010

[150] K. Iekushi, F. Seeger, B. Assmus, A. M. Zeiher, and S. Dimmeler, "Regulation of cardiac microRNAs by bone marrow mononuclear cell therapy in myocardial infarction," Circulation, vol. 125, no. 14, pp. 1765-1773, 2012.

[151] A. Caporali and C. Emanueli, "MicroRNAs in postischemic vascular repair," Cardiology Research and Practice, vol. 2012, Article ID 486702, 7 pages, 2012.

[152] H. Masumoto, T. Matsuo, K. Yamamizu et al., "Pluripotent stem cell-engineered cell sheets reassembled with defined cardiovascular populations ameliorate reduction in infarct heart function 
through cardiomyocyte-mediated neovascularization," STEM CELLS, vol. 30, no. 6, pp. 1196-1205, 2012.

[153] J. Fujita, Y. Itabashi, T. Seki et al., "Myocardial cell sheet therapy and cardiac function," The American Journal of PhysiologyHeart and Circulatory Physiology, vol. 303, no. 10, pp. H1169H1182, 2012.

[154] H. Masumoto, T. Ikuno, M. Takeda et al., "Human iPS cellengineered cardiac tissue sheets with cardiomyocytes and vascular cells for cardiac regeneration," Scientific Reports, vol. 4, article 6716, 2014.

[155] D. Zhang, W. Huang, B. Dai et al., "Genetically manipulated progenitor cell sheet with diprotin A improves myocardial function and repair of infarcted hearts," The American Journal of Physiology-Heart and Circulatory Physiology, vol. 299, no. 5, pp. H1339-H1347, 2010.

[156] H. Kobayashi, T. Shimizu, M. Yamato et al., "Fibroblast sheets co-cultured with endothelial progenitor cells improve cardiac function of infarcted hearts," Journal of Artificial Organs, vol. 11, no. 3, pp. 141-147, 2008.

[157] J. V. Terrovitis, R. R. Smith, and E. Marbán, "Assessment and optimization of cell engraftment after transplantation into the heart," Circulation Research, vol. 106, no. 3, pp. 479-494, 2010. 

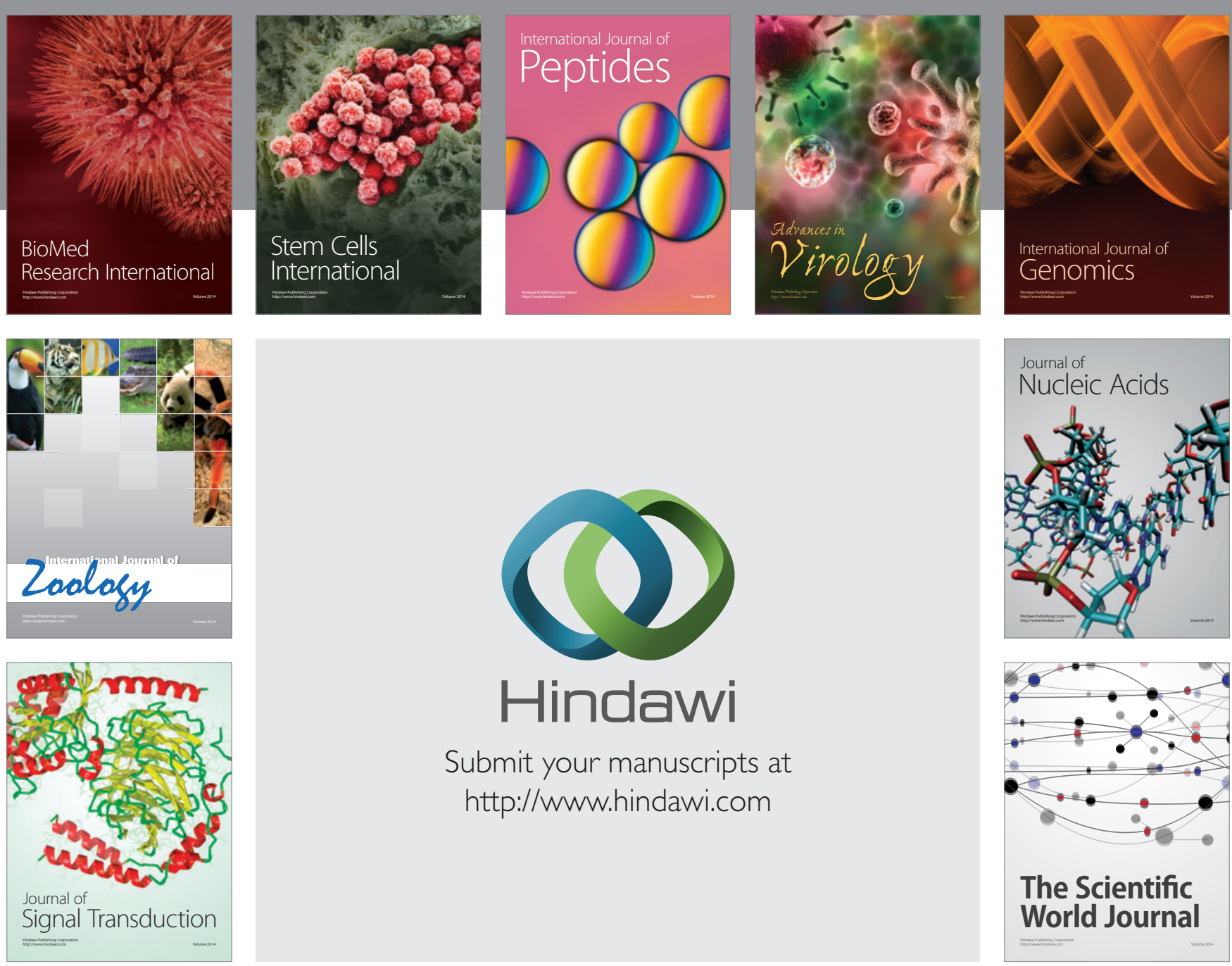

Submit your manuscripts at

http://www.hindawi.com
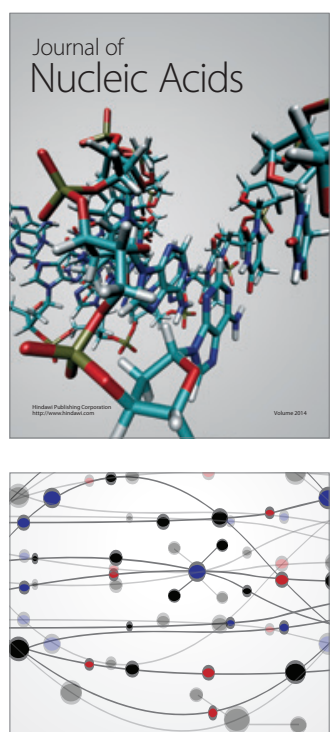

The Scientific World Journal
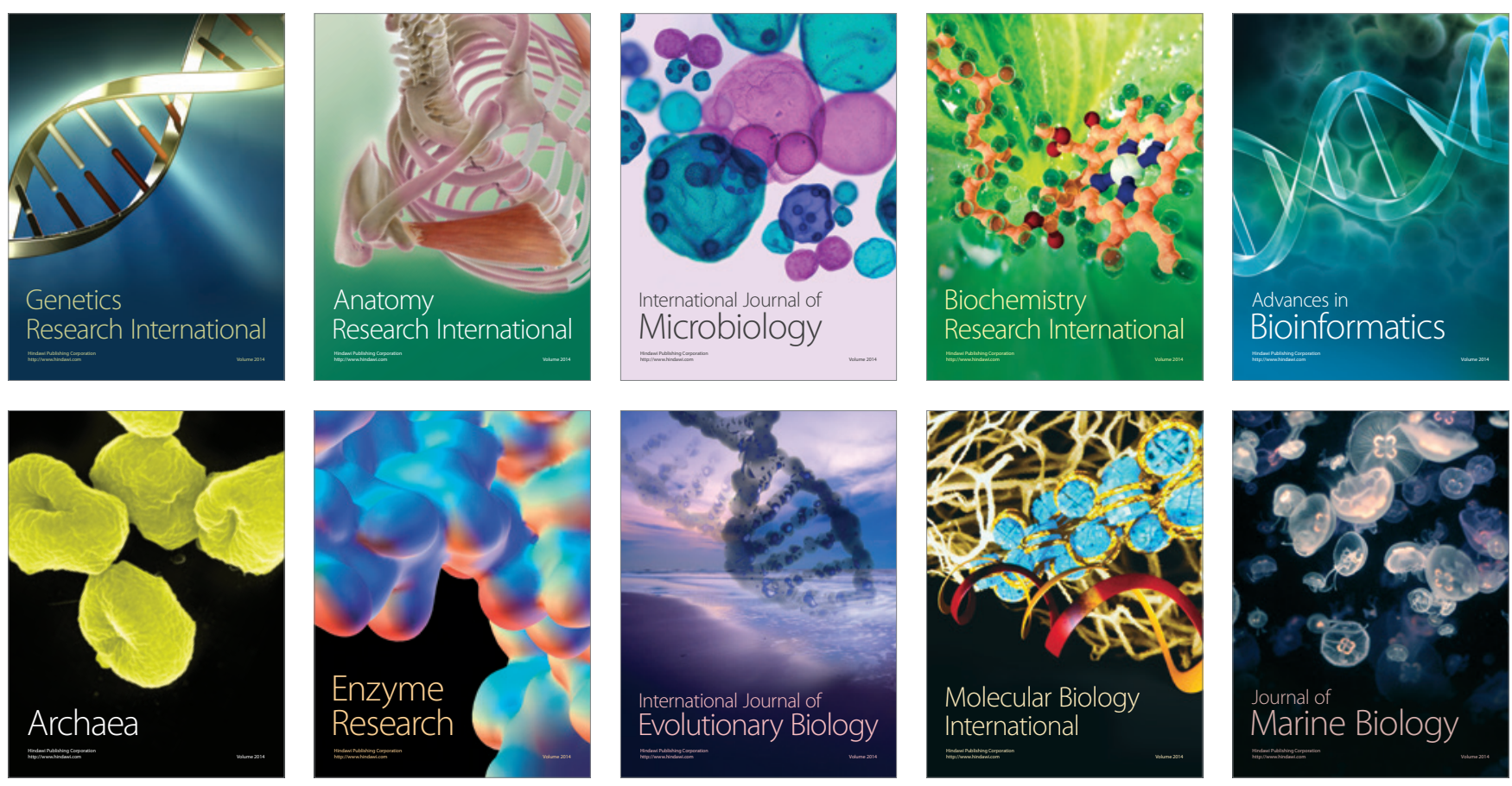